\title{
Benzodiazepine Intoxication in a Neonate by Maternal Use in Pregnancy
}

\author{
Bittmann S*, Villalon G, Weissenstein A and Luchter E \\ Department of Pediatrics, Ped Mind Institute, Germany
}

*Corresponding author: Stefan Bittmann MD, MA, Department of Pediatrics, Ped Mind Institute, Hindenburgring 448599

Gronau, Germany, Tel: 0049-2565-97325; Fax: 0049-2565-97324; Email: stefanbittmann@gmx.de

\begin{abstract}
The abuse of benzodiazepines by pregnant women can cause intoxication in the neonate. Benzodiazepines can diffuse readily across the placenta to the fetus because of their high lipid solubility. After the sixth month of pregnancy, the loss of the cytotrophoblasts from the placenta further facilitates the transport of benzodiazepines across the placenta. They may persist for at least a week in pharmacologically active concentrations after administration of high dosages to the mother. We report about a floppy, drowsy and pulmonary impaired newborn delivered in the $36^{\text {th }}$ week of gestation. The mother was a regular user of clorazepate, a long-acting benzodiazepine during pregnancy.
\end{abstract}

Keywords: Benzodiazepine; Withdrawal; Neonate; Pregnancy

Received Date: May 20, 2019; Accepted Date: June 24, 2019; Published Date: July 01, 2019

\section{Introduction}

Benzodiazepines (BZDs) are one of the most commonly used groups of anxiolytic drugs in Europe. They are most frequently prescribed to women of reproductive age and to pregnant women for reducing anxiety and managing preeclampsia or eclampsia in the latter part of pregnancy. BZDs are used commonly, even in the absence of complete knowledge of their potential adverse effects. For nearly all current benzodiazepines, the physiological action of the drug has not been fully described. It is known, that BZDs cross the placenta rapidly and reach considerably higher concentrations in cord plasma than in maternal plasma during early pregnancy and at term [1-3]. In most cases the neonate is capable of slowly metabolizing small doses of benzodiazepines, although active metabolites may persist for at least a week in pharmacologically active concentrations after administration of high dosages to the mother [1]. We report the case of a female preterm newborn with benzodiazepine withdrawal due to maternal use of these drugs during the whole pregnancy.

\section{Case Report}

The child was born in the $36^{\text {th }}$ week of gestation and delivered by c-section. Birth weight was 3320 g. APGAR was $5 / 6 / 7$ at 1,5 and $10 \mathrm{~min}$. Maternal insulin-dependent diabetes and depressions were present in pregnancy. Due to this fact the mother Citation: Stefan Bittmann, Benzodiazepine Intoxication in a Neonate by Maternal Use in Pregnancy. J Clin Cases Rep 2(4): 106-108. DOI: https://doi.org/10.46619/joccr.2019.2-1050 
http://www.tridhascholars.org | October-2019

took clorazepate and fluctine, a selective serotonine re-uptake inhibitor orally during the whole pregnancy. Desmethyldiazepam blood level in the newborn was $647 \mu \mathrm{g} / \mathrm{l}$. A muscular hypotonia and drowsiness was present. Hypoglycemia was treated with glucose infusions. Echocardiography, transcranial sonography and newborn screening for hypothyreosis, adrenogenital syndrome, galactosemia and glucose-6-phosphate dehydrogenase showed normal results. Symptoms were relieving soon and the child recovered rapidly from its impaired status. Further hospital stay was uncomplicated for the child. In the mother, amytryptylin therapy was initiated a few days after delivery.

\section{Discussion}

Benzodiazepine compounds fall into three major categories: long-, intermediate- and short acting compounds. Chlorazepate is a long-acting benzodiazepine similar to diazepam. The physiological action of the drug has not been fully described. The effects of these drugs appear to be mediated through the inhibitory neurotransmitter gamma-aminobutyric acid (GABA). Benzodiazepines appear to act on the limbic, thalamic, and hypothalamic levels of the central nervous system to produce sedative and hypnotic effects, reduction of anxiety, anticonvulsant effects, and skeletal muscle relaxation. Respiratory depression, bradycardia, and hypotension can also occur. Symptoms of neonatal intoxication include hypertonia, hyperreflexia, restlessness, restlessness, irritability, abnormal sleep patterns, inconsolable crying, tremors or jerking of the extremities, bradycardia, cyanosis, suckling difficulties, apnoea, risk of aspiration of feeds, diarrhoea and vomiting, and growth retardation. This neonatal withdrawal can appear within a few days to three weeks after birth. Laegreid et al. [4] reported in 1987 a specific "benzodiazepine syndrome" among seven infants with dysmorphism in a prospective study in which 36 mothers of 37 infants regularly took benzodiazepines during pregnancy. These results were not supported by later studies [5]. The teratogenic potential of benzodiazepines remains controversial, but is probably small if it exists at all. In a follow-up study up to 4 years no increase of malformation rate or adverse effects on neuro-behavioural development and IQ after benzodiazepine withdrawal was found [6]. Enterodialysis in a newborn with benzodiazepine withdrawal was reported once, in which treatment was successful [6]. Symptomatic older children require hospital admission. Treatment is largely supportive. The use of flumazenil, a competitive antagonist, is not generally indicated in neonates and children. The use of flumazenil should be restricted to patients in whom adequate measures to protect the airway, support respiration, and maintain circulation have failed [7-9].

\section{References}

1. Mandelli M, Morselli PL, Nordio S, et al. (1975) Placental transfer of diazepam and its disposition in the newborn. Clinical Pharmacology \& Therapeutics 17(5): 564-572.

2. Erkkola R, Kangas L, Pekkarinen A (1973) The transfer of diazepam across the placenta during labour. Acta Obstetricia et Gynecologica Scandinavica 52(2): 167-170.

3. Kanto J, Erkkola R, Sellman R (1973) Accumulation of diazepam and N-demethyldiazepam in the fetal blood during the labour. Annals of Clinical Research 5(6): 375-379.

4. Laegreid L, Olegard R, Wahlström J, et al. (1987) Abnormalities in children exposed to benzodiazepines in utero. The Lancet 329(8524): 108-109.

5. McElhatton PR (1994) The effects of benzodiazepine use during pregnancy and lactation. Reproductive Toxicology 8(6): 461-475. 
6. Malgorn G, Leboucher B, Harry P, et al. (2004) Benzodiazepine poisoning in a neonate: clinical and toxicokinetic evaluation following enterodialysis with activated charcoal. Archives de Pediatrie: Organe Officiel de la Societe francaise de Pediatrie 11(7): 819-821.

7. Kanto JH (1982) Use of benzodiazepines during pregnancy, labour and lactation, with particular reference to pharmacokinetic considerations. Drugs 23(5): 354-380.

8. Rey E, Giraux P, d'Athis P, et al. (1979) Pharmacokinetics of the placental transfer and distribution of clorazepate and its metabolite nordiazepam in the feto-placental unit and in the neonate. European Journal of Clinical Pharmacology 15(3): 181-185.

9. Patel DA, Patel AR (1980) Clorazepate and congenital malformations. JAMA 244(2): 135-136. 